\title{
Transmembrane serine protease 2 is a prognostic factor for lung adenocarcinoma
}

\author{
MARC A. SCHNEIDER ${ }^{1,2}$, SARAH RICHTMANN $^{1-3}$, ANNA R. GRÜNDING $^{4,5}$, SABINE WRENGER $^{4,5}$, \\ TOBIAS WELTE ${ }^{4,5}$, MICHAEL MEISTER ${ }^{1,2}$, MARK KRIEGSMANN ${ }^{2,6}$, HAUKE WINTER ${ }^{2,7}$, \\ THOMAS MULEY ${ }^{1,2}$ and SABINA JANCIAUSKIENE ${ }^{4,5}$
}

\author{
${ }^{1}$ Translational Research Unit, Thoraxklinik at Heidelberg University Hospital, D-69126 Heidelberg; \\ ${ }^{2}$ Translational Research Center Heidelberg (TLRC), Member of The German Center for Lung Research (DZL); \\ ${ }^{3}$ Division of Systems Biology of Signal Transduction, German Cancer Research Center (DKFZ), D-69120 Heidelberg; \\ ${ }^{4}$ Department of Respiratory Medicine, Hannover Medical School; ${ }^{5}$ Biomedical Research in End-stage and \\ Obstructive Lung Disease Hannover (BREATH), Member of The German Center for Lung Research (DZL), \\ D-30625 Hannover; ${ }^{6}$ Institute of Pathology, Heidelberg University Hospital, D-69120 Heidelberg; \\ ${ }^{7}$ Department of Surgery, Thoraxklinik at Heidelberg University Hospital, D-69126 Heidelberg, Germany
}

Received October 13, 2021; Accepted January 31, 2022

DOI: 10.3892/ijo.2022.5329

\begin{abstract}
Transmembrane serine protease 2 (TMPRSS2) has been intensively investigated during the current Sars-CoV-2 pandemic as a virus activating protease. Furthermore, TMPRSS2 is an oncogenic gene associated with several cancer entities. Co-expression of TMPRSS2 and serpin family A member 1 (SERPINA1) (encoding alpha-1-antitrypsin; AAT) has been reported in the human lung. Recently, AAT was identified as a novel TMPRSS2 inhibitor. We previously reported that lower SERPINA1 expression in tumor tissues and higher levels of plasma AAT are associated with worse survival of patients with non-small cell lung cancer (NSCLC). In the present study, we sought to examine TMPRSS2 and SERPINA1/AAT expression in tumor and adjacent lung tissues from 347 NSCLC patients. Based on clinical data and gene expression analysis, we performed Cox regression for the survival analysis, and correlated TMPRSS2 and AAT protein levels in tissue samples by immunohistochemical and western blot analyses. We found that lower TMPRSS2 expression in tumor compared to adjacent non-tumor tissues is linked to a poor overall survival in patients with adenocarcinoma (ADC) and those who are current smokers. IHC staining of TMPRSS2 validated our findings in regard to overall survival while we did not observe a correlation with AAT staining. Based on western blot analyses, we found only a slight negative correlation
\end{abstract}

Correspondence to: Dr Sabina Janciauskiene, Department of Respiratory Medicine, Hannover Medical School, Carl-Neuberg-Str. 1, D-30625 Hannover, Germany

E-mail: janciauskiene.sabina@mh-hannover.de

Key words: lung cancer, TMPRSS2, SERPINA1, alpha1-antitrypsin, prognostic factor between full-length TMPRSS2 and AAT in non-tumor tissues, which seems to be related to smoking status. Taken together, we demonstrated that TMPRSS2 is a prognostic factor in patients with lung ADC; however, a link between AAT and TMPRSS2 proteins warrants further investigation.

\section{Introduction}

Non-small cell lung cancer (NSCLC) accounts for about $85 \%$ of all lung cancer cases whereas adenocarcinoma (ADC) and squamous cell carcinoma (SQCC) are the two major histological subtypes (1). As a heterogeneous disease, NSCLC is a challenge for treatment, and the 5-year survival rate of patients with advanced tumor stages is still low (2). Therefore, it is of critical importance to uncover the molecular mechanism(s) behind NSCLC progression.

We recently reported that expression levels of serpin family A member 1 (SERPINA1), a gene-encoding alpha1-antitrypsin (AAT), are significantly lower in tumor tissue of both the SQCC and ADC subtypes of NSCLC compared to levels noted in adjacent normal lung tissue (3). Remarkably, higher expression of the SERPINAl gene in tumor tissue, especially in smokers, was associated with better overall and disease-free survival.

As mentioned above, the product of the SERPINA1 gene is AAT, an acute-phase serum glycoprotein and a broad-spectrum inhibitor of serine proteases. Several research groups have demonstrated that AAT reduces acute lung injury by suppressing inflammation and cell death. Interestingly, a recent study identified AAT as an inhibitor of transmembrane serine protease 2 (TMPRSS2) activity (4), a protease which plays a role in the cellular entry of coronaviruses, including Severe Acute Respiratory Syndrome Coronavirus Type 2 (SARS-CoV-2), SARS-CoV, and Middle East Respiratory Syndrome (MERS)-CoV, as well as influenza viruses. Recent research, based on pseudoparticles and replication-competent 
viruses, are in line with the above observation as AAT prevents an early step in the viral life cycle, and selectively inhibits SARS-CoV-2 spike but not Vesicular stomatitis virus glycoprotein (VSV-G)-mediated infection, which is independent from TMPRSS2 activation (5). Understanding how TMPRSS2 protein expression varies in the lungs could reveal important insights into differential susceptibility to influenza and coronavirus infections but also into cancer development. In general, patients with cancer seem to be more susceptible to SARS-CoV (6). Specifically, cancer type, staging and anticancer therapies seem to be additional risk factors for severe COVID-19 (7).

Intriguingly, a recent study provided evidence that tumor tissue from head and neck cancer patients have reduced expression of TMPRSS2 when compared to non-tumorous tissues (8). According to the experimental data, SARS-CoV-infected TMPRSS2-knockdown (-/-) mice show weakened inflammatory chemokine and/or cytokine responses, lower virus spread within the airways and less severe immunopathology (9). Hence, hypothetically TMPRSS 2 may be a cancer-suppressor gene or reflect tumorigenic processes. Multiple studies have shown that in prostate, lung, and other cancer cells, TMPRSS2 is regulated by the androgen receptor, a nuclear receptor, and a member of the steroid receptor family $(10,11)$. TMPRSS2 is expressed as a 70-kDa full-length form and has a $32-\mathrm{kDa}$ protease domain, which is cleaved and secreted after autocleavage (12). The increased activity of TMPRSS2 mediates signal transduction between cancer cells and the extracellular environment, and thus determines different cellular responses (13). Specifically, TMPRSS2 can cleave and activate protease-activated receptor 2 (PAR2), which triggers the release of inflammatory mediators, immune cell recruitment, tumor cell invasion, and apoptosis (14). PAR2 receptor signaling in the airway epithelium also causes calcium release (12) suggesting a role for TMPRSS2 in the pathogenesis of cancer pain (13).

In the present study, we aimed to investigate RNA and protein levels of TMPRSS2 in NSCLC patients and their associations with survival prognosis. We also aimed to clarify whether there is any relationship between TMPRSS2 and SERPINA1 expression, and TMPRSS2 and AAT protein levels.

\section{Materials and methods}

Sample collection, characterization and preparation. Tissue samples were provided by the Lung Biobank Heidelberg, a member of the accredited Tissue Bank of the National Center for Tumor Diseases (NCT) Heidelberg, the Biomaterial Bank Heidelberg, and the Biobank Platform of the German Center for Lung Research (DZL). The local ethics committees of the Medical Faculty Heidelberg and Hannover Medical School [S-270/2001 (biobanking vote) and 9155_BO_K_2020 (study-specific vote)] approved the use of the biomaterial and data. All patients (for cohort overview see Table I) included in the study signed an informed consent, and the study was performed according to the principles set out in the WMA Declaration of Helsinki.

Tumor and matched distant $(>5 \mathrm{~cm})$ tumor-free lung tissue samples from NSCLC patients who underwent therapy-naive resection for primary lung cancer at Thoraxklinic at University Hospital Heidelberg, Germany were collected between 2006 and 2011. Tissues were snap-frozen within $30 \mathrm{~min}$ after resection and stored at $-80^{\circ} \mathrm{C}$ until the time of analysis. More detailed information is provided elsewhere (15).

Total RNA isolation and cDNA synthesis. RNA was isolated from tumor tissue and adjacent lung tissue. For RNA isolation from patient tumor tissue, a tumor content of $\geq 50 \%$ was the minimum prerequisite. A total of 10-15 tumor cryosections $(10-15 \mu \mathrm{m})$ from each patient were sliced, and the first as well as the last section of the series was stained with hematoxylin and eosin (H\&E). A lung pathologist determined the proportion of viable tumor cells, stromal cells, healthy lung cells, and necrotic areas. Total RNA was isolated from patient tissue using an AllPrep DNA/RNA/miRNA Universal kit (Qiagen, Inc.) according to the manufacturer's instructions. Afterwards, the quality of total RNA was assessed by utilizing an Agilent 2100 Bioanalyzer and an Agilent RNA 6000 Nano kit (Agilent Technologies). Using the Transcriptor First Strand cDNA Synthesis kit (Roche), total RNA was transcribed to complementary DNA and used for quantitative polymerase chain reaction (qPCR). A complete description of the procedure is provided elsewhere (15).

Real-time polymerase chain reaction (RT-PCR) analysis. For gene expression analyses of patient tissues, volumes of $5 \mu \mathrm{l}$ cDNA (corresponding to $5 \mathrm{ng}$ of isolated total RNA) were utilized for qPCR with the LightCycler $480^{\circledR}$ (Roche) in 384-well plates according to the Minimum Information for Publication of qPCR Experiments (MIQE) guidelines (16). Universal ProbeLibrary (UPL) assay (Roche) was used as the amplification and detection system. Gene-specific primers (TIB Molbiol were combined with the primaQuant 2X qPCR Probe-MasterMix (Steinbrenner Laborsysteme). Threshold cycle $(\mathrm{Ct})$ values were evaluated with the LightCycler $480^{\circledR}$ software release 1.5 and the 2 nd derivative maximum method (Roche). For the comparison of gene expression in tumor and non-malignant samples, the relative expression of the genes was calculated ( $\Delta \mathrm{Ct}$ values). A panel of housekeeper genes was evaluated in tumor and lung samples in regard to stable expression, and TMPRSS2 expression was normalized to the housekeepers esterase D (ESD) and ribosomal protein S18 (RPS18). For the waterfall plots analyzing the fold-change expression changes between tumor and normal tissues, the $2^{-\Delta \Delta \mathrm{Ct}}$ values were calculated. The following primers and UPL were used for the detection of TMPRSS2: TMPRSS2 forward (UPL \#71, 5'-ACCAGTGTGTCTGCC CAAC-3') and TMPRSS2 reverse (UPL \#71, 5'-GCGTTC AGCACTTCTGAGG-3'); ESD forward (UPL\#50, 5'-TCA GTCTGCTTCAGAACATGG-3') and ESD reverse (UPL\#50 5'-CCTTTAATATTGCAGCCACGA-3'); RPS18 forward (UPL\#46, 5'-CTTCCACAGGAGGCCTACAC-3') and RPS18 reverse (UPL\#46, 5'-CGCAAAATATGCTGGAACTTT-3'). The complete procedure including housekeeper selection is described elsewhere (15).

Western blot analyses of TMPRSS2 and AAT. Cryo-conserved tumor and corresponding lung tissues from patients were evaluated by a pathologist as described in the 'Total RNA 
Table I. Patient data of the qPCR cohort.

Cohort description

\begin{tabular}{|c|c|c|}
\hline Parameters & $\mathrm{n}$ & $(\%)$ \\
\hline Total & 347 & 100 \\
\hline Median age (years) & $65(38-88)$ & \\
\hline \multicolumn{3}{|l|}{ Sex } \\
\hline Male & 240 & 69 \\
\hline Female & 107 & 31 \\
\hline \multicolumn{3}{|l|}{ Histology } \\
\hline Adenocarcinoma & 204 & 59 \\
\hline Squamous & 143 & 41 \\
\hline \multicolumn{3}{|l|}{ Therapy } \\
\hline $\mathrm{OP}$ & 203 & 59 \\
\hline OP/RT & 11 & 3 \\
\hline $\mathrm{OP} / \mathrm{ChT}$ & 97 & 28 \\
\hline OP/RT/ChT & 36 & 10 \\
\hline \multicolumn{3}{|l|}{ Smoking status } \\
\hline Non-smoker & 36 & 10 \\
\hline Ex-smoker & 183 & 53 \\
\hline Smoker & 126 & 36 \\
\hline No data & 2 & 1 \\
\hline \multicolumn{3}{|l|}{ Pathological stage } \\
\hline \multicolumn{3}{|l|}{ (7th TNM edition) } \\
\hline IA & 34 & 10 \\
\hline IB & 89 & 26 \\
\hline IIA & 71 & 20 \\
\hline IIB & 47 & 14 \\
\hline IIIA & 94 & 27 \\
\hline IIIB & 12 & 3 \\
\hline \multicolumn{3}{|l|}{ ECOG } \\
\hline 0 & 297 & 86 \\
\hline 1 & 46 & 13 \\
\hline 2 & 4 & 1 \\
\hline
\end{tabular}

OP, surgery; ChT, chemotherapy; RT, radiotherapy; ECOG, Easter Cooperative Oncology Group; TNM, tumor-node-metastasis.

isolation and cDNA synthesis' section and cut in $100-\mu \mathrm{m}$ pieces with a HM 500 OM microm (Thermo Fisher Scientific, Inc.). Tissues were disrupted using $500 \mu 1 \mathrm{PBS}$ (\#14190-094, Thermo Fisher Scientific, Inc.) per $100 \mathrm{mg}$ of tissue, Halt ${ }^{\mathrm{TM}}$ Protease Inhibitor Cocktail (\#78430, Thermo Fisher Scientific, Inc.) and a TissueLyser Mixer-Mill Disruptor (Qiagen) for $2 \mathrm{~min}$ at $25 \mathrm{~Hz}$. Afterwards, the cell lysates were centrifuged for $10 \mathrm{~min}$ at $13.000 \mathrm{x} \mathrm{g}$ and $4^{\circ} \mathrm{C}$. The supernatants were transferred to a new tube, and the protein concentration was determined using a BCA protein assay (\#23225, Thermo Fisher Scientific, Inc.). A total of 24 randomly selected patients were used as representative examples. Total protein $(100 \mu \mathrm{g})$ was used for the immunoblot analysis of TMPRSS2 and AAT and heated for $5 \mathrm{~min}$ at $95^{\circ} \mathrm{C}$ in an SDS (sodium dodecyl sulfate)-sample buffer containing ß-mercaptoethanol, glycine and pyronin. Samples were separated using 10\% SDS-PAGE and blotted on a nitrocellulose membrane (\#GE10600002 Merck KGaA) that was blocked with nonfat dried milk powder (5\%, \#A0830, AppliChem) in PBS/Tween 20 (0.1\%, \#A4974, AppliChem) for $1 \mathrm{~h}$ at room temperature. For the detection of TMPRSS2, a rabbit monoclonal antibody (\#MA5-35756, Thermo Fisher Scientific, Inc.) was applied at a dilution of 1:750 overnight at $4^{\circ} \mathrm{C}$. For the detection of AAT, a rabbit polyclonal antibody (\#A0012, Dako) was used at a dilution of 1:10,000 overnight at $4^{\circ} \mathrm{C}$. A $\beta$-actin antibody (\#A5441 Merck KGaA) was applied at a dilution of 1:10,000 for $1 \mathrm{~h}$ at room temperature as a loading control. A peroxidase system was used for signal development. A secondary anti-mouse IgG antibody (\#A4416, Merck KGaA) was applied at a dilution of 1:10,000 for $1 \mathrm{~h}$ at room temperature, and a secondary anti-rabbit IgG antibody (\#A6154, Merck KGaA) was applied at a dilution of 1:5,000. Signals were visualized with Chemiluminate-HRP Picodetect (\#A3417, Applichem). Quantification of the signals was evaluated with Image Studio Lite V. 5.2 (LI-COR Biosciences, $\mathrm{GmbH}$ ) and adapted to actin levels (Figs. S3-S6).

Immunohistochemical analyses. For detection of TMPRSS2, a monoclonal TMPRSS2 antibody (MABF2158, Merck $\mathrm{KGaA}$ ) was used. Before tissue microarray (TMA) construction, a H\&E-stained slide of each block was analyzed to select tumor-containing regions. A TMA machine (AlphaMetrix Biotech) was used to extract tandem 1.0-mm cylindrical core sample from each tissue donor block (for cohort overview see Table II). Paraffin-embedded tissue sections were deparaffinized with the following steps: $2 \times 10 \mathrm{~min}$ in xylol, $2 \times 5 \mathrm{~min}$ in $100 \%$ ethanol, $1 \times 3 \mathrm{~min}$ in $98 \%$ ethanol and $1 \times 3 \mathrm{~min}$ in $70 \%$ ethanol. Antigen retrieval was performed in a steamer with sodium-citrate-buffer $(10 \mathrm{mM}$ sodium citrate, $0.05 \%$ Tween $20, \mathrm{pH}$ 6.0) for $15 \mathrm{~min}$. Peroxidases were blocked for $10 \mathrm{~min}$ at room temperature (RT) using $3 \%$ $\mathrm{H}_{2} \mathrm{O}_{2}$ (Applichem). Slides were incubated with normal goat serum for $1 \mathrm{~h}$ at RT to avoid unspecific background staining (Cell Signaling Technology, Inc.). The primary antibody was incubated at a dilution of 1:200 overnight at $4^{\circ} \mathrm{C}$ in a humid chamber. The staining procedure was performed with SignalStain ${ }^{\circledR}$ DAB Substrate Kit (\#8059, Cell Signaling Technology, Inc.) according to manufacturer's instructions. The last developing step was performed for $2 \mathrm{~min}$. Cell nuclei were stained using Mayer's Hematoxylin Solution (Sigma-Aldrich/Merck KGaA). Slides were mounted using ImmunoHistoMount $^{\mathrm{TM}}$ (Sigma-Aldrich/Merck KGaA). Staining was observed with an Olympus IX-71 inverted microscope. Images were captured with an Olympus Color View II digital camera and Olympus Cell-F software (cellSense dimension, V1.11, Olympus). Tiffs were assembled into figures using Photoshop CS6 (Adobe Systems, Inc.). Only changes in brightness and contrast were applied. TMA slides were scanned and analyzed using Aperio ImageScope (v12.4.3.5008, Leica Biosystems). Scoring was performed by multiplication of staining intensity (0-3) with the proportion of positive cells (0-4) (Fig. 4A).

Statistical analyses. Data of qPCR and IHC analyses were statistically analyzed under REMARK criteria (17) with 
Table II. Patient data of the IHC cohort.

Cohort description

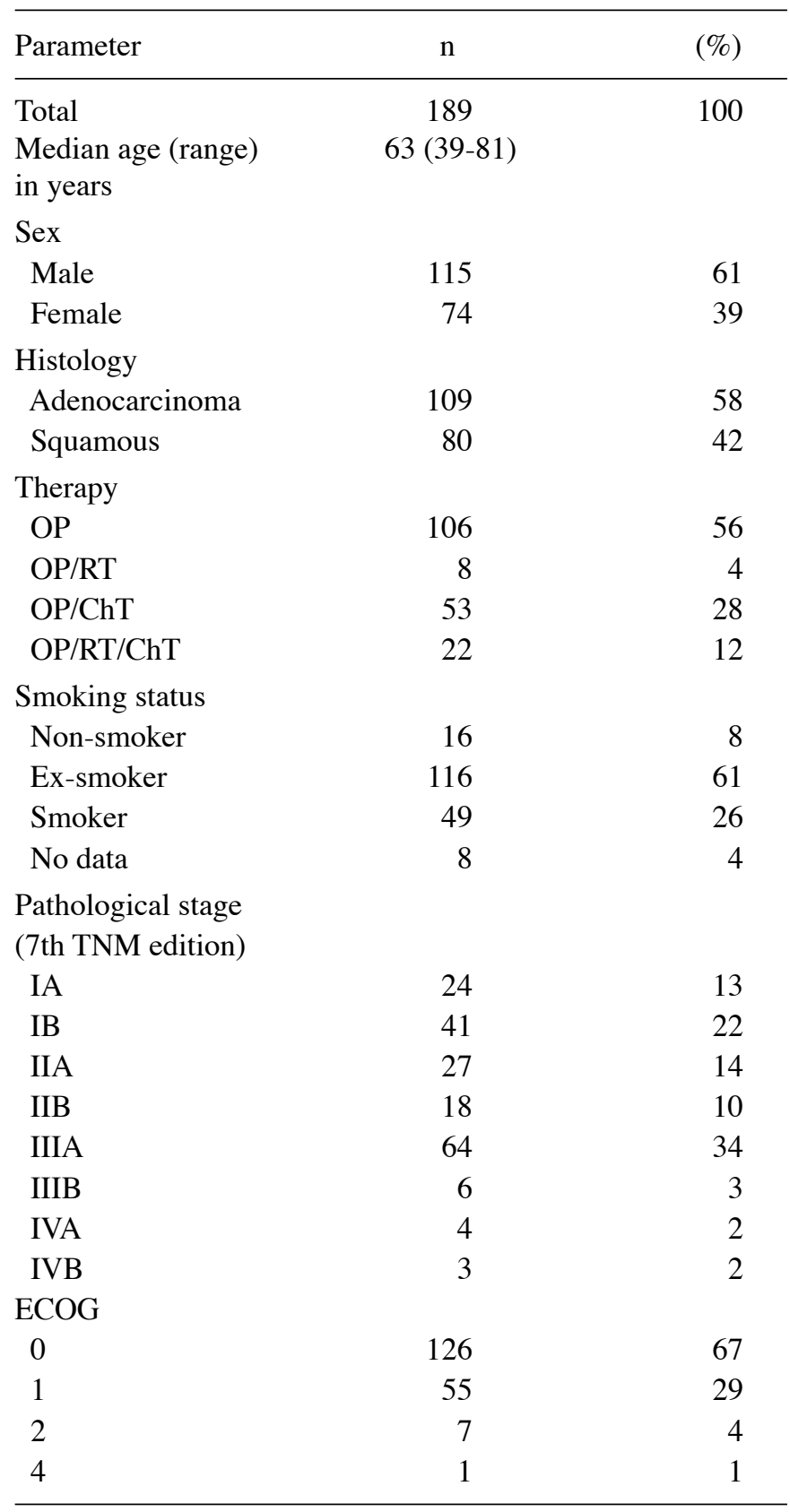

IHC, immunohistochemistry; OP, surgery; ChT, chemotherapy; RT, radiotherapy; ECOG, Easter Cooperative Oncology Group; TNM, tumor-node-metastasis.

SPSS 25.0 for Windows (IBM Corp.). The endpoint of the study was overall survival. Overall survival time was calculated from the date of diagnosis until the last date of contact or death. The cut-offs used for survival analyses were selected using the software tool 'Cutoff-Finder' (http://molpath. charite.de/cutoff/index.jsp). Multivariate survival analyses were performed using the Cox proportional hazards model (Table III). Univariate analysis of survival data was performed according to Kaplan and Meier (Figs. 1C-F, 2 and 4). The log-rank test was used to test the significance between the groups. The non-parametric, Wilcoxon matched-pairs signed rank test and the Mann-Whitney test were used to investigate significant differences between the patient groups (Figs. 1A, 4D and S1). The Bonferroni's correction for multiple testing was considered for Fig. 1A. Correlation analyses were performed using the nonparametric Spearman's rank correlation analysis (Figs. 3, 4B, 5C and D and S2). A P-value $<0.05$ was considered significant. Data were visualized with GraphPad Prism 9 (GraphPad Software, Inc.) and SPSS 25.0 (IBM Corp.).

\section{Results}

Lower expression of the TMPRSS2 gene in tumor tissues of NSCLC patients is a prognostic factor for overall survival. First, we analyzed TMPRSS 2 gene expression in a large NSCLC patient cohort $(n=347$, Table I). We observed a significantly lower expression of TMPRSS2 in the tumor tissues of patients with SQCC and ADC compared to that noted in the adjacent non-tumor lung tissues (Fig. 1A; Please note that higher values indicate a lower expression). TMPRSS2 was significantly upregulated in pathological stage I ADC compared to stage II, but not in SQCC (Fig. S1; Please note that higher values indicate a lower expression). Comparing tumor and normal lung tissues, we found an approximately 10-fold downregulation of TMPRSS2 in the tumor tissues of patients with SQCC and an approximately 2-fold downregulation in the tumor tissues of patients with ADC (Fig. 1B). In the SQCC group, TMPRSS2 was downregulated in $137 / 143$ patients ( 96\%, Fig. 1B).

In a further approach, we focused on the influence of TMPRSS 2 on patient overall survival. We used the software Cut-off Finder to separate patients into two groups: one with a higher and one with a lower TMPRSS2 expression. A multivariate survival analysis (Table III) including the most important clinical parameters of the entire NSCLC cohort revealed that age $(\mathrm{HR}=1.036, \mathrm{P}=0.001)$, sex (male vs. female, $\mathrm{HR}=1.502$, $\mathrm{P}=0.041)$ pathological tumor stage $(\mathrm{HR}=1.032, \mathrm{P}<0.001)$ and a low expression of TMPRSS2 $(\mathrm{HR}=1.536, \mathrm{P}=0.033)$ are independent prognostic indicators of a dismal prognosis (Table III). A more detailed analyses of the two subgroups of NSCLC revealed that age and pathological tumor stage are prognostic indicators for both, SQCC and ADC, patients. However, the lower expression of TMPRSS 2 was found as a significant independent prognostic factor only for $\mathrm{ADC}(\mathrm{HR}=2.065$, $\mathrm{P}=0.002$ ) (Table III). A low expression of TMPRSS2 resulted in a more than 2-fold hazard ratio. Kaplan-Meier analyses including all patients (Fig. 1C) confirmed that low TMPRSS2 expression in tumor tissue is prognostic for poor overall survival $(\mathrm{P}=0.017)$. In contrast, the expression of TMPRSS 2 in adjacent normal lung tissue was not correlated with survival prognosis (Fig. 1D). Remarkably, we found that low TMPRSS2 expression had a prognostic value only for patients harboring an ADC $(\mathrm{P}=0.006)$ (Fig. 1F) but not for patients with SQCC $(\mathrm{P}=0.736$ (Fig. 1E).

Prognostic value of TMPRSS2 depends on smoking status and sex. A recent publication demonstrated an increased expression of TMPRSS2 in lung airway of smokers compared to non-smokers (18). Therefore, we further analyzed TMPRSS2 in relationship to the smoking status (Fig. 2). Indeed, we found that the prognostic effect of TMPRSS2 expression depends on 
A

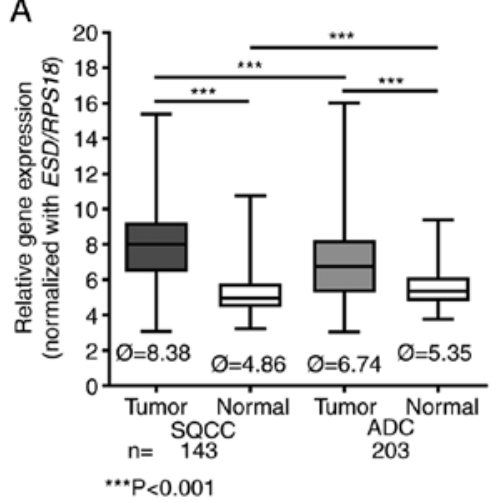

B

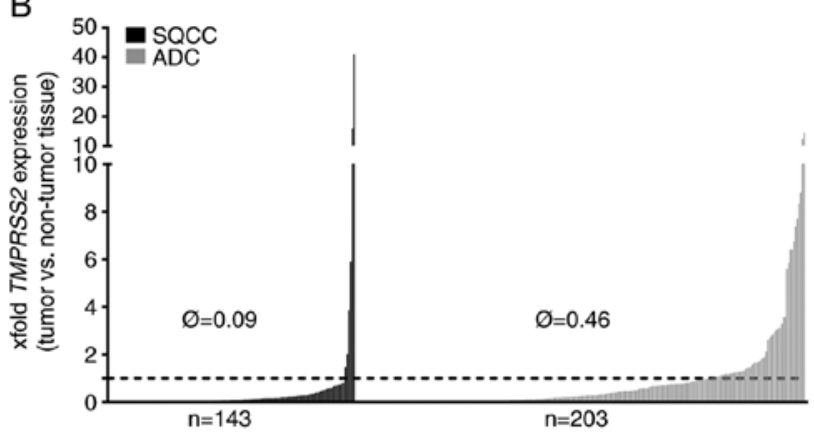

C

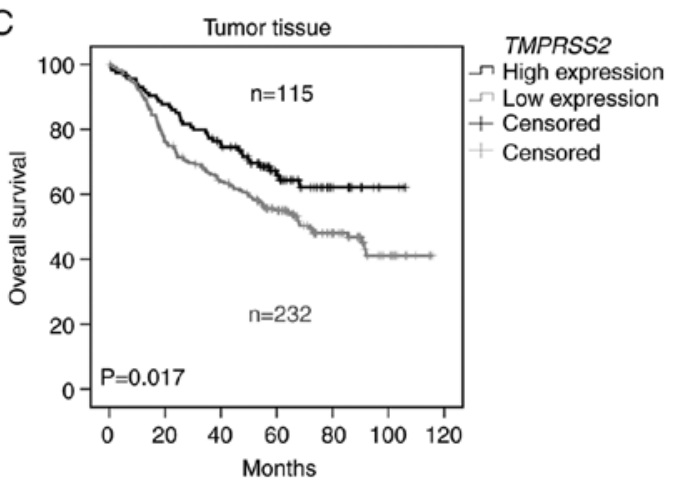

E

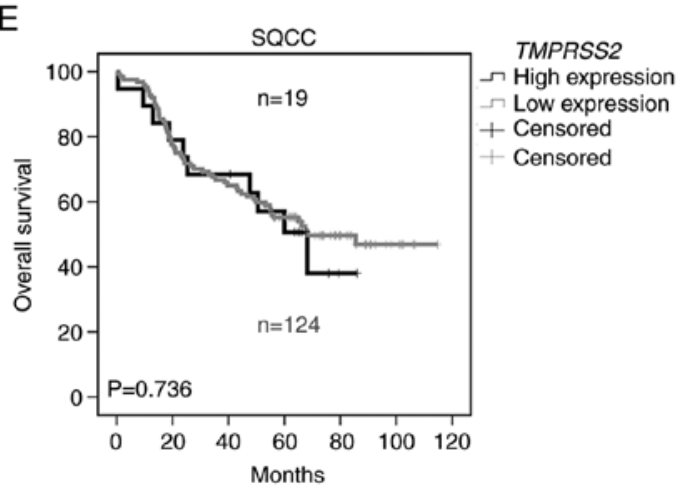

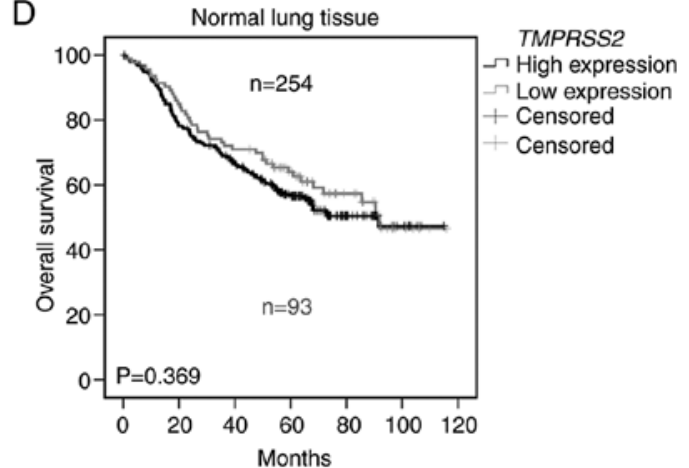

$\mathrm{F}$

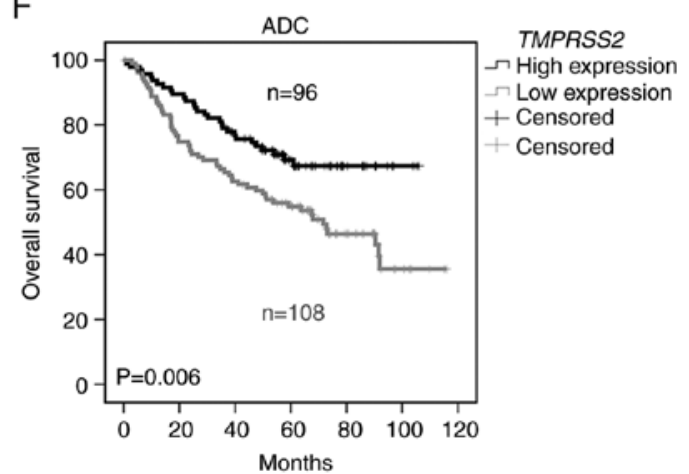

Figure 1. Expression of TMPRSS2 in NSCLC. (A) Relative expression $(\triangle \mathrm{Ct})$ of TMPRSS2 in tumor and normal lung tissues of NSCLC patients. Please note that higher values indicate a lower expression. (B) x-fold expression levels in patients with SQCC and ADC. Dotted line indicates equal TMPRSS2 expression in tumor and normal lung tissue. (C and D) Overall survival analyses of patients with high or low TMPRSS2 expression in tumor (C) or normal lung tissue (D). (E and F) Overall survival analyses of patients with high or low TMPRSS2 expression in SQCC (E) or ADC (F). Cut-offs were generated using the software Cut-off Finder. TMPRSS2, transmembrane serine protease 2; NSCLC, non-small cell lung cancer; SQCC, squamous cell carcinoma; ADC, adenocarcinoma; $\emptyset$, median. Bonferroni's correction for multiple testing was considered. $\mathrm{P}<0.025$ was considered significant.

the smoking history. While TMPRSS2 expression had no influence on overall survival in non-smokers (Fig. 2A, $\mathrm{P}=0.395$ ), a trend was observed for former smokers (Fig. 2B, $\mathrm{P}=0.172$ ) and a significantly worse prognosis was noted in current smokers (Fig. 2C, P=0.014) with lower TMPRSS2 expression in tumor tissue. Since TMPRSS2 is an androgen-regulated gene (19), we analyzed its relationship to sex. We observed a tendency for male patients (Fig. 2D) and a nearly significant survival benefit in female patients expressing higher levels of the TMPRSS2 gene in the lungs $(\mathrm{P}=0.059$, Fig. 2E).

Expression of TMPRSS2 and SERPINA1 genes is correlated in normal lung and SQCC, but not in ADC tissues. AAT has been shown to inhibit TMPRSS2 activity (4). Moreover, TMPRSS2 and SERPINA1 are co-expressed in human lungs
(GTEx Multi Gene Query. GTEx Portal 2020. https://gtexportal. org/home/multiGeneQueryPage/TMPRSS2,SERPINA1). These facts prompted us to perform correlation analyses between TMPRSS 2 and SERPINA1 expression in our NSCLC patient cohort (Fig. 3). Overall, we found a weak correlation ( $\mathrm{r}=0.44)$ between TMPRSSI and SERPINAl expression in NSCLC tumor tissues (Fig. 3A). However, in normal lung tissues, the correlation between these two genes was higher ( $\mathrm{r}=0.56$, Fig. 3B).

When we further stratified NSCLC cases into SQCC and ADC, we found that TMPRSS 2 and SERPINA1 genes were correlated in SQCC ( $\mathrm{r}=0.51$, Fig. $3 \mathrm{C})$ but not in the ADC subgroup ( $\mathrm{r}=0.24$, Fig. 3D).

TMPRSS2 protein level has prognostic value for overall survival but does not correlate with AAT staining. We next 
Table III. Multivariate analysis.

All patients

\begin{tabular}{|c|c|c|}
\hline Variable & Significance (P-value) & Hazard ratio $(95 \% \mathrm{CI})$ \\
\hline Age (years) & 0.001 & $1.036(1.016-1.056)$ \\
\hline Sex (male vs. female) & 0.041 & $1.502(1.018-2.216)$ \\
\hline Histology (ADC vs. SQCC) & 0.450 & $0.873(0.614-1.242)$ \\
\hline ECOG & 0.062 & $1.430(0.983-2.080)$ \\
\hline Pathological stage & $<0.001$ & $1.032(1.020-1.043)$ \\
\hline Smoking status & 0.166 & $1.149(0.944-1.399)$ \\
\hline TMPRSS2 expression (low vs. high) & 0.033 & $1.536(1.035-2.279)$ \\
\hline
\end{tabular}

Squamous cell carcinoma

\begin{tabular}{lrr}
\hline Variable & Significance (P-value) & Hazard ratio (95\% CI) \\
\hline Age & $\mathbf{0 . 0 3 1}$ & $\mathbf{1 . 0 3 3}(\mathbf{1 . 0 0 3 - 1 . 0 6 5 )}$ \\
Sex (male vs. female) & $\mathbf{0 . 0 3 5}$ & $\mathbf{2 . 4 8 3}(\mathbf{1 . 0 6 7 - 5 . 7 7 6 )}$ \\
ECOG & 0.17 & $1.462(0.850-2.515)$ \\
Pathological stage & $\mathbf{0 . 0 0 3}$ & $\mathbf{1 . 0 2 7}(\mathbf{1 . 0 0 9 - 1 . 0 4 6 )}$ \\
Smoking status & 0.315 & $1.281(0.791-2.075)$ \\
TMPRSS2 expression (low vs. high) & 0.299 & $0.692(0.346-1.386)$ \\
\hline
\end{tabular}

Adenocarcinoma

\begin{tabular}{|c|c|c|}
\hline Variable & Significance (P-value) & Hazard ratio $(95 \% \mathrm{CI})$ \\
\hline Age (years) & 0.003 & $1.040(1.013-1.067)$ \\
\hline Sex (male vs. female) & 0.081 & $1.591(0.945-2.681)$ \\
\hline ECOG & 0.332 & $1.119(0.892-1.045)$ \\
\hline Pathological stage & $<0.001$ & $1.037(1.022-1.053)$ \\
\hline Smoking status & 0.305 & $1.266(0.807-1.987)$ \\
\hline TMPRSS2 expression (low vs. high) & 0.002 & $2.065(1.308-3.260)$ \\
\hline
\end{tabular}

CI, confidence interval; ECOG, Easter Cooperative Oncology Group; TMPRSS2, transmembrane serine protease 2. P-values indicating statistical significance are shown in bold print.

performed IHC staining for TMPRSS2 using tissue microarrays (TMA) to include protein expression data in our analyses. In total, 104 patients with ADC and 84 patients with SQCC were evaluated (Fig. 4A). Each patient was evaluated in duplicates for the proportion of positive tumor cells (upper panel) and intensity of staining (lower panel). The total IHC score for each patient was calculated by multiplication of both values. Out of all the evaluated IHC patients, 95 were from the qPCR cohort presented in Fig. 1. As shown in Fig. 4B, protein and RNA levels of TMPRSS2 showed a slight correlation. The same TMAs were evaluated for AAT expression in our previous study (3). While AAT was detected heterogeneously and found in both tumor and stroma (Fig. 4C, left panels), TMPRSS2 protein mainly occurred in tumor cells (Fig. 4C, right panels). While AAT protein levels were similar between ADC and SQCC (Fig. 4D), TMPRSS2 levels were significantly higher in ADC than that noted in SQCC. Furthermore, we found that high protein levels of TMPRSS2 are associated with better patient overall survival (Fig. 4E) and have prognostic value for $\operatorname{ADC}(\mathrm{P}=0.006$, Fig. 4G), but not for SQCC (Fig. 4F). This latter finding is in line with our gene expression data (Fig. 1E and F). However, we did not find any correlation between TMPRSS2 and AAT protein levels in the tissue samples analyzed (Fig. S2).

Since AAT has been described as an inhibitor of TMPRSS2 activity (4), we further investigated TMPRSS2 and AAT protein profiles in NSCLC patients. Therefore, we homogenized normal and tumor tissues (tumor content $>50 \%$ ) from 24 randomly selected patients (12 SQCC and 12 ADC). Equal amounts of proteins were separated electrophoretically followed by western blot analyses (Fig. 5A). By using specific anti-TMPRSS2 and anti-AAT antibodies we were able to detect various molecular forms of TMPRSS2 (upper panels) and AAT (lower panel) proteins. Using semi-quantitative densitometric analyses, we compared the protein profiles of TMPRSS2 in tumor and normal samples (Figs. 5B and S3-S6). We observed an increased amount of TMPRSS2 
A

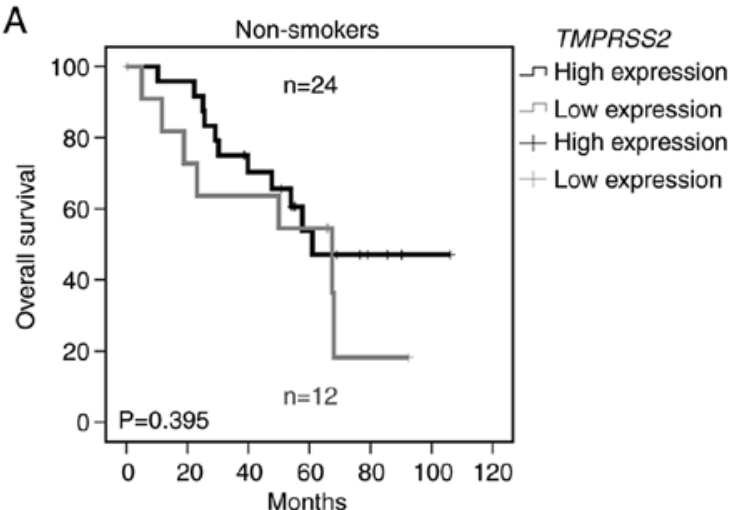

B

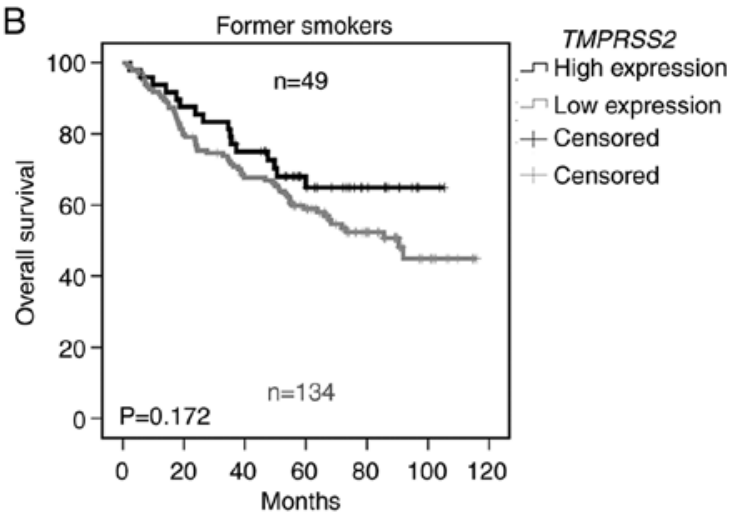

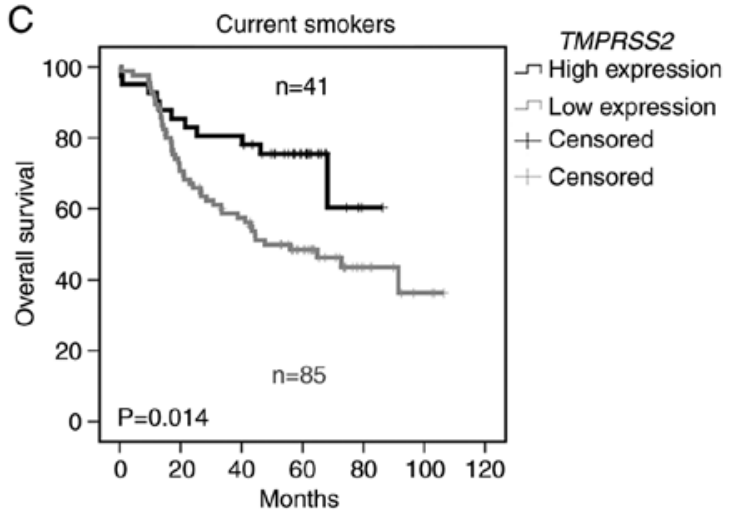
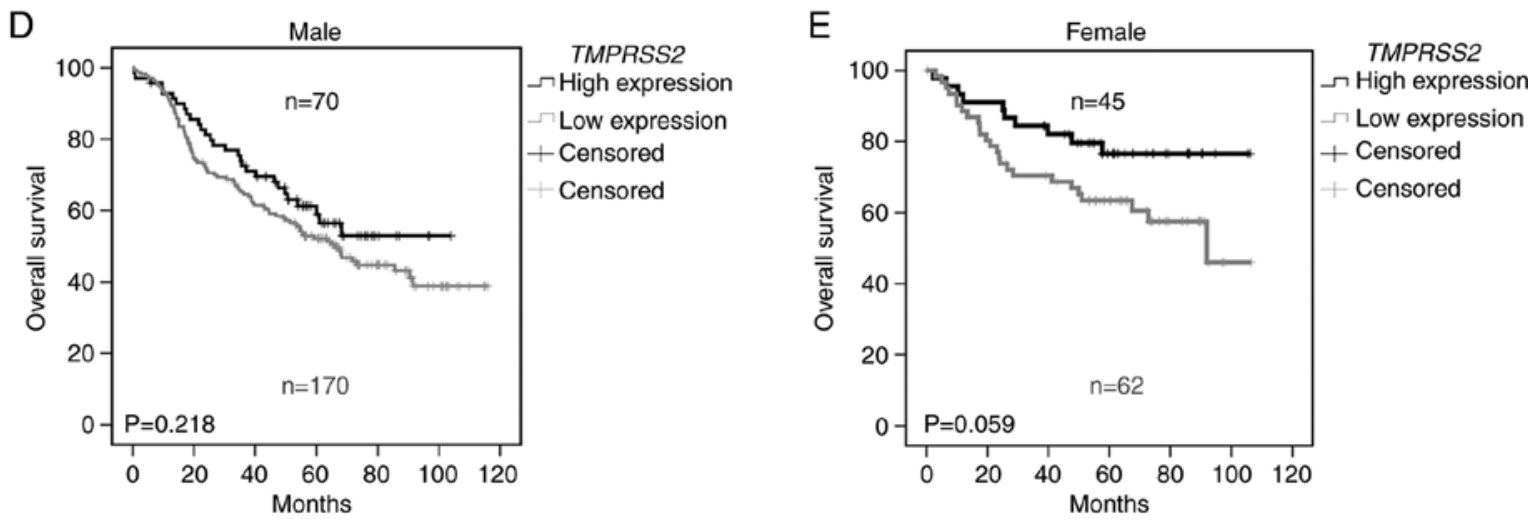

Figure 2. Overall survival analyses of NSCLC patients in relation to TMPRSS2 expression, smoking status and sex. (A-C) Kaplan-Meier plots of overall survival with regard to smoking status. The same cut-off was used as in Fig. 1C. 'Former smokers' means patients who quit smoking at any time prior to lung cancer diagnosis. Current smokers mean patients who were still smoking at the date of surgery. (D and E) Kaplan-Meier plots of overall survival with regard to sex. TMPRSS2, transmembrane serine protease 2; NSCLC, non-small cell lung cancer.

cleaved form in tumor tissues of both SQCC and ADC (with a median increase of 238 and $359 \%$, respectively). The levels of full-length TMPRSS2 and AAT protein were lower in SQCC (73\% for TMPRSS2 and AAT) and ADC (87\% for TMPRSS2 and $69 \%$ for AAT) as compared to normal lung tissues. We further investigated the relationship between TMPRSS2 and AAT protein levels and did not find any correlation in patients with SQCC (Fig. 5C). Interestingly, a slight negative correlation between the two proteins was found in normal lung tissues of patients with SQCC and ADC (Fig. 5D).

\section{Discussion}

Lung cancer is a leading cause of cancer-related death worldwide and is linked to tobacco smoking and persistent inflammation (20). To date, the molecular pathogenesis of lung cancer remains incompletely defined, and the differences in molecular signatures between adenocarcinoma (ADC) and squamous cell carcinoma (SQCC), two predominant subtypes of non-small cell lung cancer (NSCLC), are not well characterized. SQCC mostly develops in smokers while $\mathrm{ADC}$ is common in people who have never smoked. Moreover, ADC and SQCC exhibit different mutation spectra and hence patients are treated with different strategies (1). Recently, Cai et al highlighted several gene sets that showed different behavioral patterns in ADC and SQCC. For example, the higher expression of genes encoding blood coagulation factors were associated with worse survival predominantly in SQCC whereas specific changes in cell cycle gene expression were associated with worse survival in ADC (21). The investigations 
A

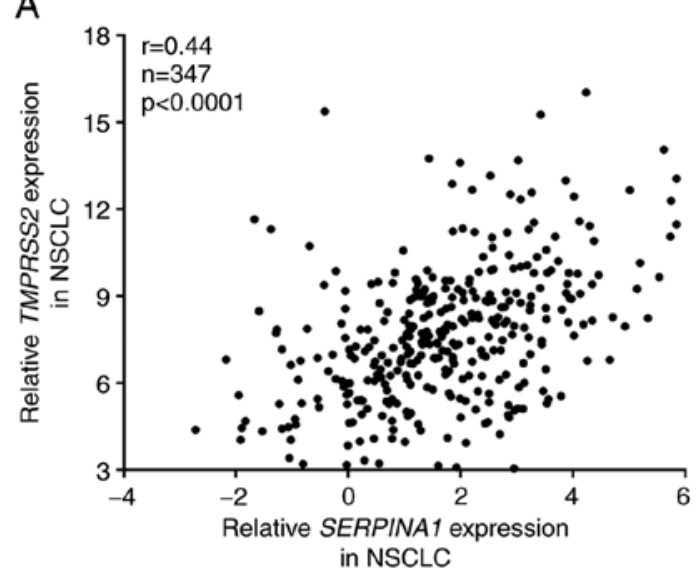

C

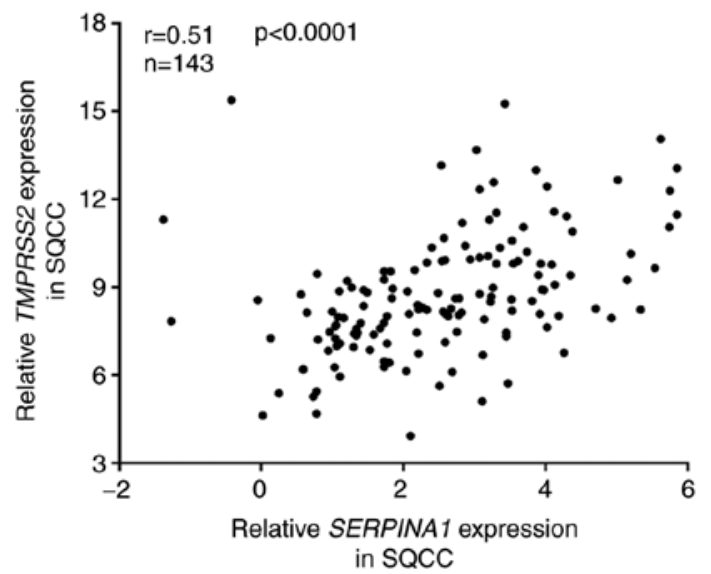

B

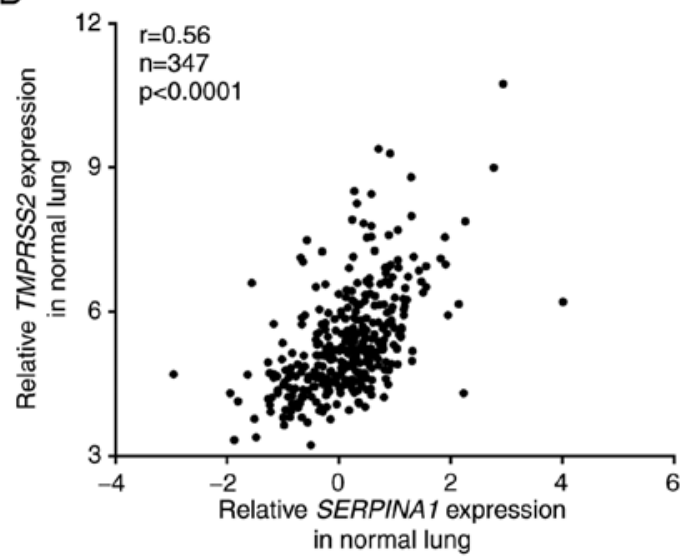

D

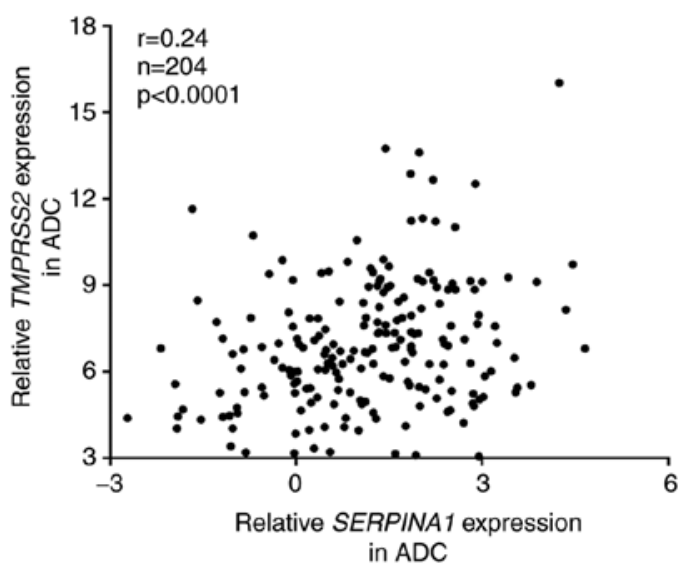

Figure 3. Correlation between TMPRSS2 and SERPINA1 expression in NSCLC. (A-D) We correlated the relative expression values of TMPRSS2 and SERPINA1 (SERPINA1 expression data taken from Ercetin et al (3) in NSCLC (A), normal lung (B), SQCC (C) and ADC (D). r $>0.5$ was considered as an adequate correlation. TMPRSS2, transmembrane serine protease 2; SERPINA1, serpin family A member 1; NSCLC, non-small cell lung cancer; ADC, adenocarcinoma; SQCC, squamous cell carcinoma.

of the genes are of clinical importance as they can provide new insights into mechanisms contributing to ADC and SQCC, and help to discover diagnostic and prognostic biomarkers for NSCLC.

Based on our previous findings that low expression of SERPINA1 (AAT encoding gene) in tumor tissues is associated with worse NSCLC patient prognosis (3), and that TMPRSS2 and SERPINA1 genes are co-expressed in human lungs (GTEx Multi Gene Query, GTEx Portal 2020, https://gtexportal.org/home/multiGeneQueryPage/TMPRSS2,SERPINA1), we aimed to investigate the relationship between SERPINA1 and TMPRSS2 expression in NSCLC patients. According to RNA and protein expression data available at Human Protein Atlas database, the lung, among all organs, has the highest TMPRSS 2 gene expression. Here we showed that patients with NSCLC have significantly lower TMPRSS2 expression in tumor than in adjacent non-tumor lung tissue. The most intriguing finding of our current study is that although a strongly reduced expression of TMPRSS2 was observed in both SQCC and ADC, only in patients harboring an ADC was TMPRSS2 gene and protein expression correlated with a poor overall survival. Our results are in concordance with recent studies showing lower levels of TMPRSS2 in lung cancer, and in head and neck cancer $(8,22)$. The fact that TMPRSS 2 expression is higher in the very early stage of the disease provides a hint that tumors benefit from reduced levels of TMPRSS2 especially when they start to metastasize. However, the biological function of TMPRSS2 remains largely unknown and available data are inconsistent. For instance, based on publicly available gene expression datasets, Asselta et al reported that TMPRSS2 expression is higher in bronchial epithelial cells of males than females, whereas the expression in the lung is similar (23). Based on three microarray datasets (GSE40419, GSE19804 and GSE10072) from NCBI GEO, Piva et al found no statistical differences in TMPRSS2 expression in lung tissues by stratifying cases for sex or smoking habits, but found a decrease in TMPRSS2 with increasing age (24). Another study, based on a different dataset analysis, reported that patients with lung cancer showed only minor changes in expression of TMPRSS2 when compared to healthy controls with identical smoking status (25). By contrast, in our large patient cohort $(n=347)$, we found significantly worse prognosis in current smokers with NSCLC having low tumor tissue expression of TMPRSS 2 relative to non-smokers or ex-smokers. These discrepancies may reflect specificities of the clinical cohorts, as the disease definition in different datasets is not always 
A

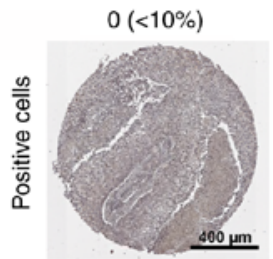

0

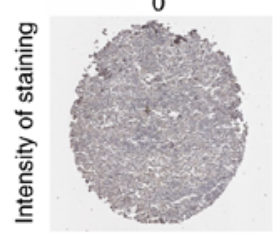

B

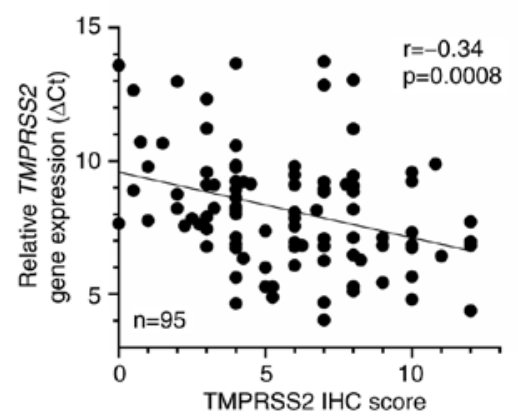

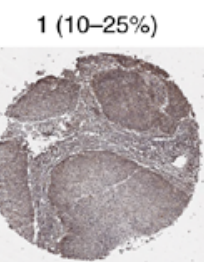

1

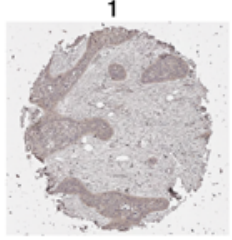

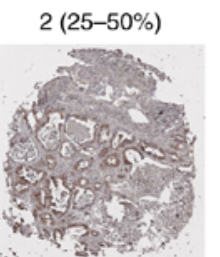

2

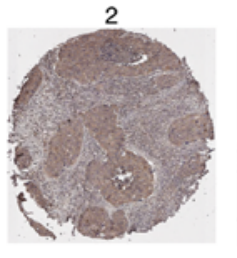

C

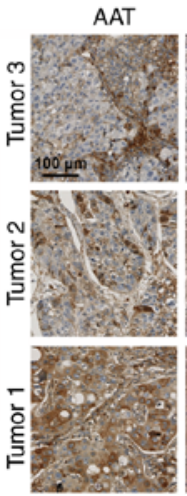

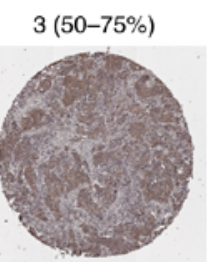

3

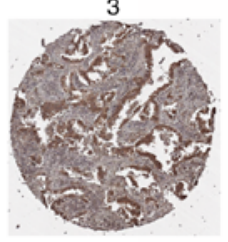

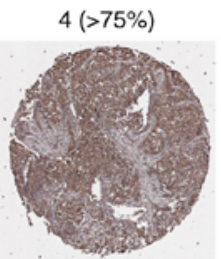

TMPRSS2

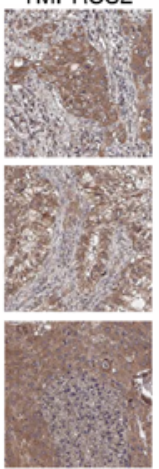

D

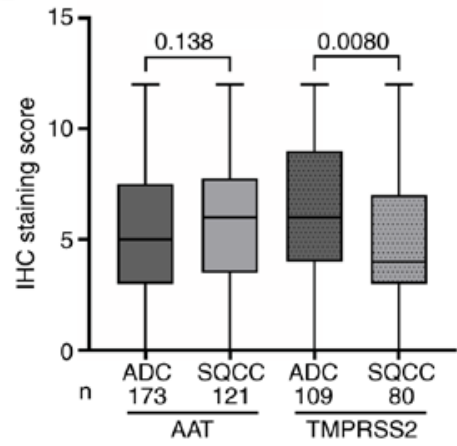

E

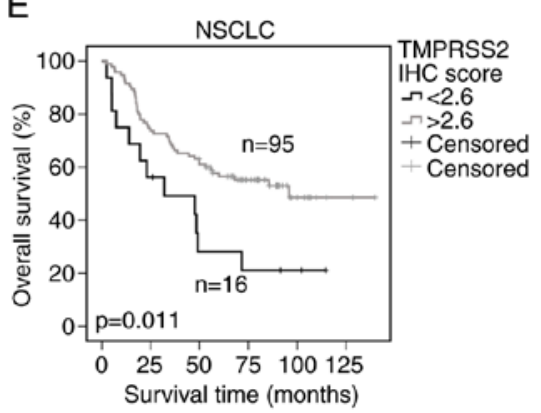

F

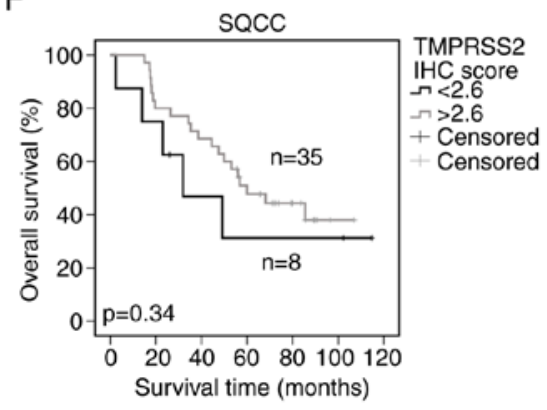

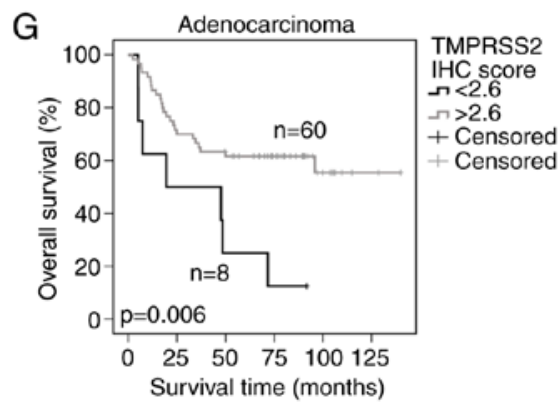

Figure 4. IHC analyses of TMPRSS2 and AAT in NSCLC patients. (A) Examples for TMPRSS2 scoring for IHC staining. (B) Correlation analyses of TMPRSS2 gene and protein expression of 95 NSCLC patients. Please note that higher $\triangle \mathrm{Ct}$ values indicate a lower gene expression. (C) Examples of AAT and TMPRSS2 IHC expression patterns. (D) AAT and TMPRSS2 IHC staining score pattern in ADC and SQCC. (E-G) Survival analyses based on TMPRSS2 IHC score in NSCLC (E), SQCC (F) and ADC (G). The tool Cut-off finder was used for calculation of the optimal cut-off. IHC, immunohistochemistry; TMPRSS2, transmembrane serine protease 2; AAT, alpha-1-antitrypsin; NSCLC, non-small cell lung cancer; ADC, adenocarcinoma; SQCC, squamous cell carcinoma.

consistent. On the other hand, specific microRNAs might target TMPRSS2 post-transcriptionally, thereby leading to its reduced expression levels in tumor tissues. All the above postulations warrant further investigations.

The TMPRSS2 protein contains a $32-\mathrm{kDa}$ extracellular serine protease domain (26). The activation of the serine protease requires its cleavage, which is autocatalytic suggesting that TMPRSS2 may be its own substrate (27). This active serine protease with trypsin-like specificity is then shed into the extracellular space, where it is predicted to interact with other proteins on the cell surface, matrix components and proteins on adjacent cells (12). 

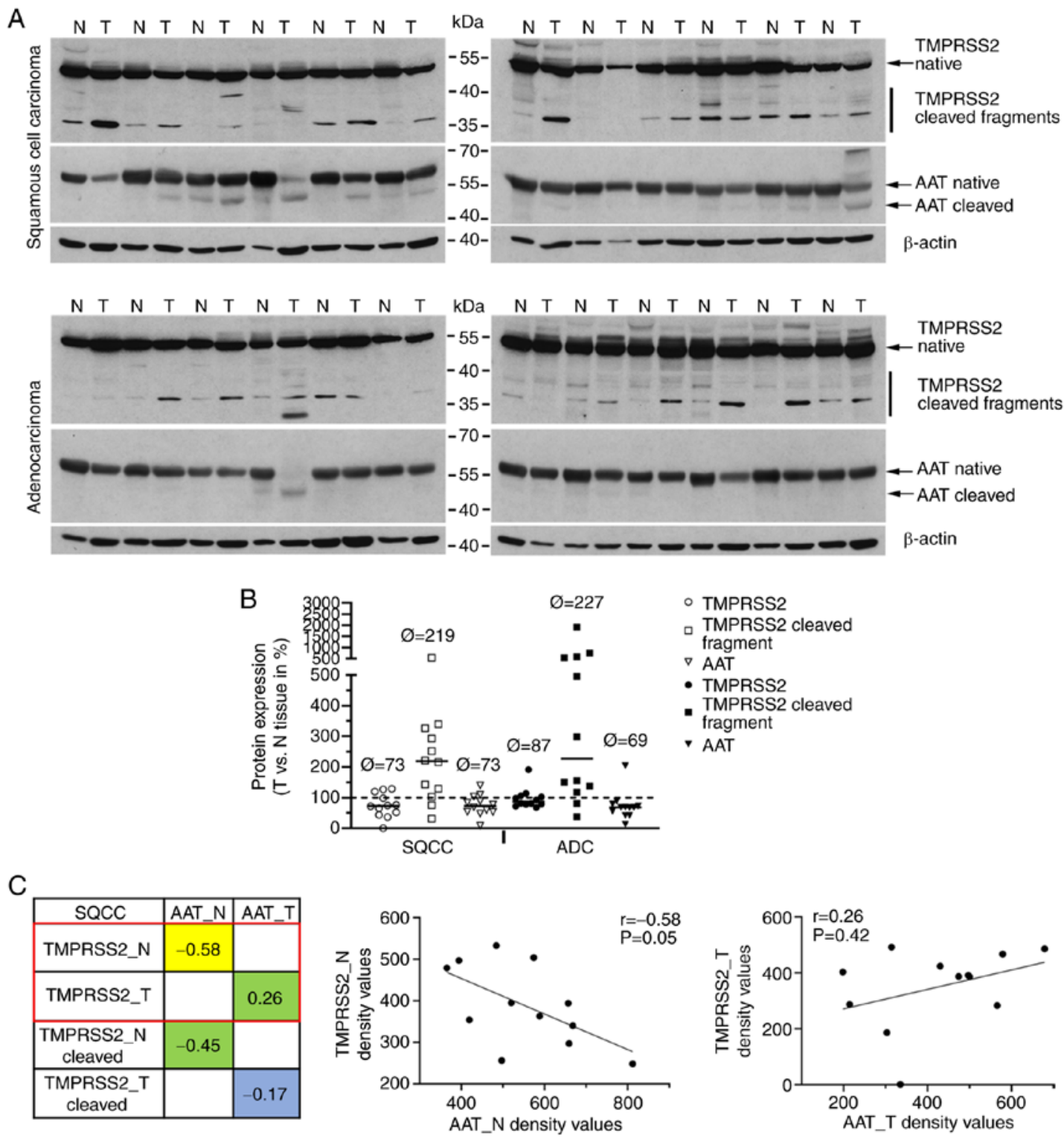

\begin{tabular}{|c|c|c|}
\hline ADC & AAT_N & AAT_T \\
\hline TMPRSS2_N & 0.26 & \\
\hline TMPRSS2_T & & 0.53 \\
\hline $\begin{array}{c}\text { TMPRSS2_N } \\
\text { cleaved }\end{array}$ & -0.39 & -0.06 \\
\hline $\begin{array}{c}\text { TMPRSS2_T } \\
\text { cleaved }\end{array}$ & & \\
\hline
\end{tabular}
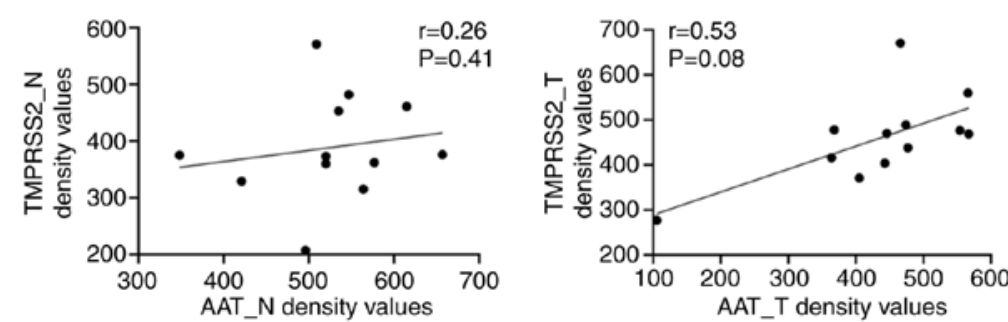

Figure 5. Expression and correlation of TMPRSS2 and AAT in NSCLC patients. (A) Western blot analyses of TMPRSS2 and AAT in 12 SQCC and ADC patient samples ( $\mathrm{N}$, normal and $\mathrm{T}$, tumor tissues). Tissues were homogenized and $100 \mu \mathrm{g}$ of each sample was used for immunoblot analysis. (B) Quantification of TMPRSS2 and AAT protein expression comparing expression values of tumor (T) and normal (N) tissues in SQCC and ADC (fold change in \%). (C and D) Correlation of TMPRSS2 and AAT protein expression in normal and tumor tissues of patient samples [(C) SQCC; (D) ADC] from A. Values in the frames are shown in more detail using correlation plots. $r>0.5$ was considered as an adequate correlation. TMPRSS2, transmembrane serine protease 2 ; AAT, alpha-1-antitrypsin; NSCLC, non-small cell lung cancer; ADC, adenocarcinoma; SQCC, squamous cell carcinoma.

We further found that in ADC tumor tissues TMPRSS2 protein is correlated with levels of AAT protein. These results show that there is a direct relationship in ADC tissue. The lower AAT protein levels within tumor tissues are correlated with a higher cleavage of TMPRSS2 protein. In general, this scenario seems to be associated with a worse survival among ADC patients.
Among others, TMPRSS2 may activate the protease activated receptor PAR2 (12) and certain metalloproteinases (MMPs) (28). Indeed, it has been reported that the expression of PAR2 is significantly upregulated in NSCLC cells (29), and that expression of MMPs is higher in ADC than in SQCC (30). It is suggested that PAR2 is involved in epithelial-mesenchymal transition in lung ADC cells and 
can serve as a therapeutic target for metastatic lung ADC and a potential biomarker for predicting the prognosis of lung ADC. These latter findings in part explain why we found that lower TMPRSS2 expression in tumor tissue is linked to a poor overall survival in patient with ADC. PAR2 is a $G$ protein-coupled receptor for trypsin as well as for TMPRRS2 (12), which after proteolytic activation contributes to growth, anti-apoptosis, and migration in lung cancer (31). Hypothetically, the inhibition of TMPRSS2 by AAT may indirectly suppress the activation of PAR2 and subsequently prevent cancer progression. Therefore, higher expression of the SERPINA1 gene and higher levels of AAT protein in tumor tissues, and lower expression of the TMPRSS 2 gene or lower cleavage of TMPRSS2 might suggest better prognosis. Consequently, we thought that correlations between SERPINAI and TMPRSS 2 genes in tumor tissues and occurrence of cleaved forms of TMPRSS2 protein may reflect a pro-tumorigenic feature of lung cancer. Unfortunately, according to IHC staining, TMPRSS2 did not correlate with AAT protein. Based on the western blot analyses, we found only a slight negative correlation between full-length TMPRSS2 and AAT proteins in non-tumor tissues of SQCC cases, which seems to be related to smoking status. Since SQCC patients are often heavy smokers, we believe that the observed negative correlation in normal lung tissues of SQCC may be related to smoking status (SQCC patients of our qPCR cohort had a median of 45 packyears as compared to 30 packyears for ADC). Moreover, ADC often develop in the distal lung while SQCC typically grows proximal to the bronchus. Consequently, normal tissue may be more distal or more proximal which might also influence the expression/correlation of both proteins.

The SERPINAl gene has been proposed as a biomarker for a variety of cancer entities, such as cutaneous squamous cell carcinoma (32), insulinomas (33), breast cancer (34) and NSCLC (35). In a large cohort of NSCLC patients, we previously reported that lower SERPINAI expression in tumor but higher in adjacent non-tumor lung tissues as well as higher serum levels of AAT protein were associated with worse survival rates (3). Moreover, according to our previous findings, higher serum levels of AAT in NSCLC patients have prognostic value for a patient's impaired outcome but do not correlate with SERPINA1 expression in tumor or non-tumor lung tissues or with staining intensities for tumor-related AAT protein. We pointed out that protein levels do not necessarily mirror gene expression, and that protein and protein-coding gene can reflect different processes in tumor biology. The circulating AAT is mainly produced and secreted by the liver (36), and can be taken up by tumor cells (3). Hence, it is possible that higher tumor levels of AAT prevent TMPRSS2 auto-cleavage or cleavage by other proteases and/or inhibit its tumorigenic activity. Although lower TMPRSS2 levels seem to be associated with a worse survival among lung cancer patients, the expression of TMPRSS 2 and SERPINA1 genes were correlated only within the normal lung tissue of SQCC and tumor tissue of ADC.

We demonstrated that TMPRSS2 is a new prognostic marker for patients with lung ADC. Our data well support the recent assumption that TMPRSS 2 and SERPINA1 genes play a role in NSCLC. However, the mechanisms regulating the associations between the two genes remain to be defined and due to limitations of sample sizes, the findings of our explorative study must be validated using a larger cohort. We plan to further extend our research focus on the interaction and correlation of TMPRSS2 and AAT using additional biobank samples. Using qPCR, we will try to distinguish between the full-length and the spliced form of TMPRSS2 to investigate which form is relevant for survival prognosis. Moreover, patient-derived cell culture models will be used to investigate the interaction of both proteins in the lung. A better understanding of the mechanisms that regulate the network of proteases and their inhibitors may identify novel approaches to disrupt processes important in cancer progression.

\section{Acknowledgements}

The authors would like to thank, Martin Fallenbüchel and Christa Stolp for the technical support.

\section{Funding}

This research was funded by the German Center for Lung Research (DZL), grant nos. 82DZL00402 and 82DZL002A1.

\section{Availability of data and materials}

The datasets used and/or analyzed during the current study are available from the corresponding author on reasonable request.

\section{Authors' contributions}

Conceptualization of the research study was achieved by MAS, SJ, and SW. Methodology was the responsibility of MAS and SJ. Software was the responsibility of MAS. Validation of the data was conducted by MAS, SJ, ARG, and TM. qPCR measurements and IHC stainings were conducted by MAS and SR. Resources were acquired by MAS, SJ, TM, HW, TW and MM. Data curation was the responsibility of MAS, SR, MK, SJ, and SW. Writing-original draft preparation was conducted by MAS and SJ. Writing-review and editing was conducted by SJ, ARG, SR, MM, MK, HW, TW and TM. Visualization was the responsibility of MAS. Supervision was performed by TM, MM, and SJ. Project administration was the responsibility of MAS and SJ. Funding acquisition was the responsibility of MM, TM, TW and SJ. All authors have read and agreed to the final version of the manuscript for publication.

\section{Ethics approval and consent to participate}

Informed consent was obtained from all subjects involved in the study. The local ethics committees of the Medical Faculty Heidelberg and Hannover Medical School (S-270/2001 and 9155_BO_K_2020) approved the use of the biomaterial and data. All patients signed a broad informed consent for the use of their samples and data for research purposes (S-270/2001). The consent is available from the corresponding author on reasonable request.

\section{Patient consent for publication}

Not applicable. 


\section{Competing interests}

The authors declare no competing interests. The funders had no role in the design of the study; in the collection, analyses, or interpretation of data; in the writing of the manuscript, or in the decision to publish the results.

\section{References}

1. Herbst RS, Morgensztern D and Boshoff C: The biology and management of non-small cell lung cancer. Nature 553: 446-454, 2018.

2. Miller KD, Nogueira L, Mariotto AB, Rowland JH, Yabroff KR, Alfano CM, Jemal A, Kramer JL and Siegel RL: Cancer treatment and survivorship statistics, 2019. CA Cancer J Clin 69: 363-385, 2019.

3. Ercetin E, Richtmann S, Delgado BM, Gomez-Mariano G, Wrenger S, Korenbaum E, Liu B, DeLuca D, Kuhnel MP Jonigk D, et al: Clinical significance of SERPINA1 gene and its encoded Alpha1-antitrypsin protein in NSCLC. Cancers (Basel) 11: 1306, 2019.

4. Azouz NP, Klingler AM, Callahan V, Akhrymuk IV, Elez K, Raich L, Henry BM, Benoit JL, Benoit SW, Noé F, et al: Alpha 1 antitrypsin is an inhibitor of the SARS-CoV-2-priming protease TMPRSS2. Pathog Immun 6: 55-74, 2021.

5. Wettstein L, Conzelmann C, Müller JA, Weil T, Groß R, Hirschenberger M, Seidel A, Klute S, Zech F, Bozzo CP, et al: Alpha-1 antitrypsin inhibits SARS-CoV-2 infection. bioRxiv: 2020

6. Gupta S, Hayek SS, Wang W, Chan L, Mathews KS, Melamed ML, Brenner SK, Leonberg-Yoo A, Schenck EJ, Radbel J, et al: Factors associated with death in critically Ill patients with coronavirus disease 2019 in the US. JAMA Intern Med 180: 1436-1447, 2020

7. Derosa L, Melenotte C, Griscelli F, Gachot B, Marabelle A, Kroemer $\mathrm{G}$ and Zitvogel L: The immuno-oncological challenge of COVID-19. Nat Cancer 1: 946-964, 2020.

8. Sacconi A, Donzelli S, Pulito C, Ferrero S, Spinella F, Morrone A, Rigoni M, Pimpinelli F, Ensoli F, Sanguineti G, et al: TMPRSS2 a SARS-CoV-2 internalization protease is downregulated in head and neck cancer patients. J Exp Clin Cancer Res 39: 200, 2020.

9. Iwata-Yoshikawa N, Okamura T, Shimizu Y, Hasegawa H, Takeda M and Nagata N: TMPRSS2 contributes to virus spread and immunopathology in the airways of murine models after coronavirus infection. J Virol 93: e01815-e01818, 2019.

10. Clinckemalie L, Spans L, Dubois V, Laurent M, Helsen C, Joniau S and Claessens F: Androgen regulation of the TMPRSS2 gene and the effect of a SNP in an androgen response element Mol Endocrinol 27: 2028-2040, 2013.

11. Leach DA, Mohr A, Giotis ES, Cil E, Isac AM, Yates LL, Barclay WS, Zwacka RM, Bevan CL and Brooke GN: The antiandrogen enzalutamide downregulates TMPRSS2 and reduces cellular entry of SARS-CoV-2 in human lung cells. Nat Commun 12: 4068, 2021.

12. Wilson S, Greer B, Hooper J, Zijlstra A, Walker B, Quigley J and Hawthorne S: The membrane-anchored serine protease, TMPRSS2, activates PAR-2 in prostate cancer cells. Biochem J 388: 967-972, 2005.

13. Lam DK, Dang D, Flynn AN, Hardt M and Schmidt BL: TMPRSS2, a novel membrane-anchored mediator in cancer pain. Pain 156: 923-930, 2015.

14. Jairaman A, Yamashita M, Schleimer RP and Prakriya M: Store-operated $\mathrm{Ca}^{2+}$ release-activated $\mathrm{Ca}^{2+}$ channels regulate PAR2-activated $\mathrm{Ca}^{2+}$ signaling and cytokine production in airway epithelial cells. J Immunol 195: 2122-2133, 2015.

15. Schneider MA, Granzow M, Warth A, Schnabel PA, Thomas M, Herth FJ, Dienemann H, Muley T and Meister M: Glycodelin: A new biomarker with immunomodulatory functions in non-small cell lung cancer. Clin Cancer Res 21: 3529-3540, 2015.

16. Bustin SA, Benes V, Garson JA, Hellemans J, Huggett J, Kubista M, Mueller R, Nolan T, Pfaffl MW, Shipley GL, et al: The MIQE guidelines: Minimum information for publication of quantitative real-time PCR experiments. Clin Chem 55: 611-622, 2009.

17. McShane LM, Altman DG, Sauerbrei W, Taube SE, Gion M, Clark GM and Statistics Subcommittee of NCI-EORTC Working Group on Cancer Diagnostics: REporting recommendations for tumor MARKer prognostic studies (REMARK). Breast Cancer Res Treat 100: 229-235, 2006.
18. Saheb Sharif-Askari N, Saheb Sharif-Askari F, Alabed M, Temsah MH, Al Heialy S, Hamid Q and Halwani R: Airways expression of SARS-CoV-2 receptor, ACE2, and TMPRSS2 is lower in children than adults and increases with smoking and COPD. Mol Ther Methods Clin Dev 18: 1-6, 2020.

19. Qiao Y, Wang XM, Mannan R, Pitchiaya S, Zhang Y, Wotring JW, Xiao L, Robinson DR, Wu YM, Tien JC, et al: Targeting transcriptional regulation of SARS-CoV-2 entry factors ACE2 and TMPRSS2. Proc Natl Acad Sci USA: Dec 11, 2020 (Epub ahead of print).

20. Siegel RL, Miller KD and Jemal A: Cancer statistics, 2020. CA Cancer J Clin 70: 7-30, 2020.

21. Cai L, Luo D, Yao B, Yang DM, Lin S, Girard L, DeBerardinis RJ, Minna JD, Xie Y and Xiao G: Systematic analysis of gene expression in lung adenocarcinoma and squamous cell carcinoma with a case study of FAM83A and FAM83B. Cancers (Basel) 11: 886, 2019.

22. Kong Q, Xiang Z, Wu Y, Gu Y, Guo J and Geng F: Analysis of the susceptibility of lung cancer patients to SARS-CoV-2 infection. Mol Cancer 19: 80, 2020.

23. Asselta R, Paraboschi EM, Mantovani A and Duga S: ACE2 and TMPRSS2 variants and expression as candidates to sex and country differences in COVID-19 severity in Italy. Aging (Albany NY) 12: 10087-10098, 2020.

24. Piva F, Sabanovic B, Cecati M and Giulietti M: Expression and co-expression analyses of TMPRSS2, a key element in COVID-19. Eur J Clin Microbiol Infect Dis 40: 451-455, 2021.

25. Yin J, Kasper B, Petersen F and Yu X: Association of cigarette smoking, COPD, and lung cancer with expression of SARS-CoV-2 entry genes in human airway epithelial cells. Front Med (Lausanne) 7: 619453, 2020.

26. Paoloni-Giacobino A, Chen H, Peitsch MC, Rossier C and Antonarakis SE: Cloning of the TMPRSS2 gene, which encodes a novel serine protease with transmembrane, LDLRA, and SRCR domains and maps to 21q22.3. Genomics 44: 309-320, 1997.

27. Afar DE, Vivanco I, Hubert RS, Kuo J, Chen E, Saffran DC, Raitano AB and Jakobovits A: Catalytic cleavage of the androgen-regulated TMPRSS2 protease results in its secretion by prostate and prostate cancer epithelia. Cancer Res 61: 1686-1692, 2001

28. Reid JC, Matsika A, Davies CM, He Y, Broomfield A, Bennett NC, Magdolen V, Srinivasan B, Clements JA and Hooper JD: Pericellular regulation of prostate cancer expressed kallikrein-related peptidases and matrix metalloproteinases by cell surface serine proteases. Am J Cancer Res 7: 2257-2274, 2017.

29. Jiang Y, Zhuo X, Fu X, Wu Y and Mao C: Targeting PAR2 overcomes gefitinib resistance in non-small-cell lung cancer cells through inhibition of EGFR transactivation. Front Pharmacol 12: $625289,2021$.

30. Thomas P, Khokha R, Shepherd FA, Feld R and Tsao MS: Differential expression of matrix metalloproteinases and their inhibitors in non-small cell lung cancer. J Pathol 190: 150-156, 2000.

31. Tsai CC, Chou YT and Fu HW: Protease-activated receptor 2 induces migration and promotes slug-mediated epithelial-mesenchymal transition in lung adenocarcinoma cells. Biochim Biophys Acta Mol Cell Res 1866: 486-503, 2019.

32. Farshchian M, Kivisaari A, Ala-Aho R, Riihilä P, Kallajoki M, Grénman R, Peltonen J, Pihlajaniemi T, Heljasvaara R and Kähäri VM: Serpin peptidase inhibitor clade A member 1 (SerpinA1) is a novel biomarker for progression of cutaneous squamous cell carcinoma. Am J Pathol 179: 1110-1119, 2011.

33. de Sa SV, Correa-Giannella ML, Machado MC, Krogh K, de Almeida MQ, Albergaria Pereira MA, Coelho Siqueira SA, Patzina RA, Ibuki FS, Sogayar MC, et al: Serpin peptidase inhibitor clade A member 1 as a potential marker for malignancy in insulinomas. Clin Cancer Res 13: 5322-5330, 2007.

34. Chan HJ, Li H, Liu Z, Yuan YC, Mortimer J and Chen S: SERPINA1 is a direct estrogen receptor target gene and a predictor of survival in breast cancer patients. Oncotarget 6: 25815-25827, 2015.

35. Zhao W, Yang Z, Liu X, Tian Q, Lv Y, Liang Y, Li C, Gao X and Chen L: Identification of alphal-antitrypsin as a potential prognostic biomarker for advanced nonsmall cell lung cancer treated with epidermal growth factor receptor tyrosine kinase inhibitors by proteomic analysis. J Int Med Res 41: 573-583, 2013.

36. Janciauskiene SM, Bals R, Koczulla R, Vogelmeier C, Kohnlein T and Welte T: The discovery of alpha1-antitrypsin and its role in health and disease. Respir Med 105: 1129-1139, 2011.

This work is licensed under a Creative Commons Attribution-NonCommercial-NoDerivatives 4.0 International (CC BY-NC-ND 4.0) License. 